\title{
Hypomandibular faciocranial dysostosis
}

INSERM

\section{Source}

INSERM. (1999). Orphanet: an online rare disease and orphan drug data base.

Hypomandibular faciocranial dysostosis. ORPHA:1790

Hypomandibular faciocranial dysostosis is a cranial malformation characterized by facial dysmorphism (proptosis, frontal bossing, midface and zygomatic arches hypoplasia, short nose with anteverted nostrils, microstomia with persistent buccopharyngeal membrane, severe hypog lossia with glossoptosis, severe mandibular hypoplasia, and low set ears) associated with laryng eal hypoplasia and craniosynostosis. Other variable features include cleft palate, optic nerve coloboma and choanal stenosis. 